\title{
Mathematical Concepts as Natural Kinds
}

[Conceitos Matemáticos como Tipos Naturais]

\section{Daniel Arvage Nagase}

\begin{abstract}
This paper presents an approach to mathematical terms similar to the approach developed by Kripke in order to deal with natural kind terms; in fact, I argue that mathematical terms are natural kind terms in the sense of Kripke. Thus, I suggest that, from a semantic perspective, such terms should be seen as primarily referring terms, and, from a metaphysical perspective, that good definitions of such terms should embody structural information about the exemplars from the kind in question.
\end{abstract}

Keywords: mathematical definitions, natural kinds, essence, structure

Resumo: Este artigo apresenta uma abordagem de termos matemáticos semelhante à abordagem desenvolvida por Kripke para lidar com termos de tipo natural; na verdade, eu defendo que termos matemáticos são termos de tipo natural no sentido de Kripke. Assim, sugiro que, a partir de uma perspectiva semântica, tais termos devem ser vistos principalmente como termos referentes, e, de uma perspectiva metafísica, que boas definições de tais termos devem incorporar informações estruturais sobre os exemplares do tipo em questão.

Palavras-chave: definições matemáticas, tipos naturais, essência, estrutura

There are at least two approaches to natural kinds: first, we can approach them from a semantic point of view, studying the semantics of terms which denote natural kinds. Second, we can approach them from a metaphysical point of view, investigating the structure of the exemplars of a given kind. In this paper, I will make some suggestions about how some of Kripke's ideas about natural kinds can be adapted to the mathematical case. I will start with the semantic approach and then use some of the issues arising from it to motivate the metaphysical approach as well. I qualify my remarks here as suggestions, instead of arguments, to indicate their provisional nature; much more needs to be done about this subject, and I will finish by pointing in what seems to me to be promising directions for further study.

${ }^{\star}$ Doutorando em filosofia pela Universidade de São Paulo (USP). E-mail: dan.nagase@gmail.com. 


\section{Semantics}

Let us start then with a quick review of Kripke's ideas regarding the semantics of natural kind terms. Following traditional usage, I call the semantic value of a term the term's contribution to the determination of the truth value of the sentences in which it occurs. Before Kripke's work, it was common to identify the semantic value of a natural kind term with a description, or a cluster of descriptions, satisfied only by the extension of the term in question. In other words, it was common to identify the semantic value of a natural kind term with what could be called its descriptive content, how the term is used to describe a given feature of reality.

Kripke's main thesis, then, is that the semantic value of a natural kind term is not its descriptive content, but rather its referencea natural kind term is used not to describe a given feature of reality, but to name it. That is, for Kripke, a natural kind term is not synonymous to a description, or cluster of descriptions, which is associated to the term by speakers of the language in which the term occurs. In particular, this means that its reference is not determined by whether some objects satisfy a given description (or cluster of descriptions), but rather by another mechanism. Since this mechanism is important for what follows, let us take a quick look at how Kripke motivates it.

Initially, according to Kripke, a term acquires reference by way of a "baptism ceremony", in which a person declares, for instance, "I will call this stuff by the term 'gold"' or "I will call by 'gold' this yellow, metallic stuff" (in the first case, the reference is fixed by a demonstrative indication, whereas in the second case it is fixed by description). After this "ceremony", the reference of a term is transmitted by a historical chain whose first link is the ceremony: as the speakers of a language intend to use the term with the same reference as the baptizer, this reference gets transmitted along the community, even if those employing the term are mistaken with respect to which description was used to fix this reference. That is why, to Kripke, reference takes precedence to description: we use a term first to refer to "this object here" or "to that object referred by (whomever)", and only later we associate a description to the term. Otherwise put, we use a term because it refers to a given object (because we want to speak about this object, and not another one), and not because we associate to it a certain description. 
As a consequence, we obtain what is usually called the stability of reference: the reference of a natural kind term is stable across changes in the descriptions associated with the term. For example, perhaps in the past the description associated with the term "gold" was something like "yellow metal", whereas now it is "chemical element with atomic number 79". But this change in the associated description does not alter the semantic value of the term, as we still refer to the same substances as gold.

The above is a very brief sketch of Kripke's views (which I will not defend here), but it will suffice for my purposes. What I want to suggest is that this view can be applied to mathematical terms as well. In particular, I want to suggest that at least some interesting examples of mathematical terms-such as "continuous" - are examples of natural kind terms, in the sense sketched above. Of course, I do not want to suggest that every mathematical predicate is a natural kind term (which is absurd). But I do want to suggest that the widespread view according to which most, if not all, mathematical definitions are stipulations or conventions that determine the semantic value of the defined terms is mistaken. According to this view, the semantic value of a mathematical term would be the result of a decision on the part of the mathematical community, in such a way that there would be an arbitrary component in the corresponding concepts. Against this, I want to suggest that the degree of arbitrariness involved in the definition of a mathematical term is generally very low.

Let us consider a typical example, the notion of something being continuous. An idealized version of the history of this notion is as follows: initially, mathematicians isolated an interesting mathematical class, noticing that they all satisfied a property that they called "continuity" (very roughly, these objects were lines or curves that could be drawn without lifting the pencil from the paper). The first characterizations of this class were derived from what we could call its phenomenal qualities, such as "being generated by the uninterrupted movement of a point". However, especially in the 19th century, developments tied to the representation of infinite series of functions and the generalization of certain concepts from real to complex analysis led to a deeper investigation of this class of functions. There were at least two goals: first, to obtain a definition of continuity that only used intrinsi- 
cally mathematical concepts and, second, to obtain a definition that could reveal a deep structural fact that explained why this class of functions is so fruitful. Both of these goals were achieved by the celebrated Weierstrass definition of continuity in terms of "espilons and deltas".

One lesson I want to draw from this narrative is the following. Suppose, for vividness, that one were to show Newton and Weierstrass paradigmatic examples of functions (say, the trigonometric functions, or a given polynomial). It is uncontroversial that they would agree in their classification of certain functions as continuous in the great majority of cases. That is, in the great majority of cases they would agree that the same functions were, or were not, continuous. But according to the descriptivist, who holds that the semantic value of a term is determined by the description associated to it, this agreement would be illusory, since Newton and Weierstrass associate different descriptions to the term "continuous", and hence actually mean different things by it. Indeed, according to this descriptivist, what we have above is not the history of the continuity notion, since there is no such a notion, but rather a succession of notions each attached to the term "continuous". That is, the term "continuous" would be ambiguous. On the other hand, if we adopt Kripke's views, there is no difficulty in saying that we do have the same notion across our narrative, a notion whose properties were progressively determined by mathematical investigation.

Another lesson to draw from the history of the mathematical notion of continuity is that there is little that is arbitrary in Weierstrass's definition. It is not that Weierstrass stipulated that, thereafter, a continuous function would be one that satisfied such and such a property. Indeed, that this was not the case is easily seen by the fact that practically every mathematician involved in the investigation of the foundations of mathematics in the 19th century agreed that a good definition of a continuous function would have to satisfy certain conditions (notably, it would have to imply the intermediate value theorem). Of course, such conditions were merely necessary, but not sufficient (not even jointly sufficient) conditions for a function to be continuous. But they did point to the demand that a good definition of continuity should explain why the continuous functions satisfied these conditions.

I cannot resist adding a further example of this idea, this time 
a little too contentious. It seems to me that Turing's analysis of computability in terms of Turing machines fits exactly the pattern described above. Mathematicians had long been interested in algorithms, and had already isolated a large class of functions as being algorithmically computable. Some of these were paradigmatic, and Turing's definition captured exactly what made them paradigmatic, by describing the computation process behind such functions. This points to a third lesson to be drawn from the above narrative. A mathematical definition is successful not when it matches some kind of pretheoretic definition, or intuition, of a given concept. This would be to accept the descriptivist thesis, according to which the definition would merely spell out the descriptive content of the term being defined. Against the descriptivist, I hold that in most cases it may be that there was no "pretheoretic" or "intuitive" description corresponding to the term. So the widespread view, according to which Turing's thesis is "unprovable", because the "intuitive" notion of computability is not rigorous enough to allow one to prove the equivalence between it and Turing's rigorous definition, gets things exactly backwards. There was no intuitive notion of compu- tability, but rather there were $p a$ radigmatic instances, and the rigorous definition is successful to the extent that it explains what makes such instances paradigmatic, what common characteristic holds together all those objects. Again, this is precisely what Turing did.

\section{Metaphysics}

The picture adumbrated above accords well with certain Aristotelian strands in Kripke's description of the scientific endeavor. According to this description, researchers start by grouping together certain objects that share given features (generally phenomenal qualities)-what the Aristotelians call a predicate profile. This predicate profile allows us to infer that such objects form a natural kind. In the second phase of the inquiry, one then looks for structural features-the essence, according to Kripke-of these objects, features that explain why the objects in question share this predicate profile. It is those structural features that ground the phenomenal qualities of the objects and explain why the initial sample constitutes a kind. Of course, in many cases the phenomenal qualities were misleading, and one is then led to rectify the initial characterization of the kind. 
From the metaphysical point of view, it is common to level the charge against Kripke that the notion of essence he employs is somewhat obscure. This is a curious charge, since his notion of essence is perfectly in order-a property is essential to an object if it is necessary that the object has that property. The problem with Kripke's notion of essence is not that it is obscure, but rather that it is inadequate. In our particular mathematical context, this inadequacy is glaring, since every property of a mathematical object is (presumably) necessary, whence every property would be essential to the object. This points to a demand for a new notion of essence that could fulfill the explanatory role indicated above.

To develop such a notion of essence is an enormous task, one that I will excuse myself from discharging here. Instead, I would like to merely indicate some possible ideas for further development. First, it seems to me that one thing we can draw from the above narrative is that this notion of essence would have to be tied to the structural characteristics of the object. It is extremely difficult to make this more precise in a non-trivial manner, but some attempts in this direction have been carried out by those who, following Kit Fine's example, are articulating a kind of Aristotelian hylemorphism. The idea here is to develop a rich enough notion of form that could distinguish between a mere heap or aggregate from a full-blown integrated object, and use this notion of form to specify the essence of a kind as its formal features. In the mathematical case, these formal features would then explain why the kind in question is natural, by exhibiting a common property that explained why certain theorems hold of the given kind (e.g. Bolzano explicitly introduced his definition of continuity in order to explain the intermediate value theorem). This last aspect is related to some problems in the philosophy of mathematical explanation: an informative proof would be one that exploited an essential feature of a given kind in order to derive a further property of the kind.

Regardless of whether a viable notion of essence can be developed, it seems clear, however, that the search for structural characteristics of mathematical objects is a driving force behind much mathematical research. One area in which related ideas have been very fertile is model theory. Take, for example, the characterization of $\aleph_{0}$-categorical theories as those with finitely many $n$-types for each $n$. This characterization 
points to an initial description of a class of theories (all their countable models are isomorphic) and proceeds to relate this to structural properties of the theories themselves (for each $n$, the space of $n$-types is finite), which explains why the initial description holds (this is very rough, but intuitively the space of $n$-types controls how much variation there can be between models of the same theory; so the smaller the space, the smaller the variation-the limit case here is when the space is compact and discrete, which im- plies that there can be no variation). The success of this program for the countable case suggests that perhaps we could attempt the general case; Shelah's classification program is precisely the extension of such ideas to the general case.

Such remarks are obviously very inchoate and were intended to be merely suggestive. But I do hope to have convinced the reader that there is at least something to this approach. If not, I must apologize for the time misspent!

\section{References}

FINE, Kit."Essence and Modality”. Philosophical Perspectives, 8 (1994), pp. 1-16.

FINE, Kit. "Senses of Essence". In: Modality, Morality, and Belief: Essays in Honor of Ruth Barcan Marcus. Ed. by Sinnott-Armstrong, Raffman, and Asher. Cambridge: Cambridge University Press, 1994, pp. 53-73.

FINE, Kit."The Logic of Essence”. Journal of Philosophical Logic, 24 (1995), pp. 241-273.

FINE, Kit."Things and Their Parts”. Midwest Studies in Philosophy, 23 (1999), pp. 61-74.

FINE, Kit. "Semantics for the Logic of Essence". Journal of Philosophical Logic, 29 (2000), pp. 543-584.

KRIPKE, Saul.Naming and Necessity. Cambridge, Massachusetts: Harvard University Press, 1980.

SHELAH, Saharon. Classification Theory and the Number of Non-Isomorphic Models. 2nd ed. Amsterdam: North-Holland, 1990. 
